\title{
The Consumption of Television Programming: Development and Validation of the Connectedness Scale
}

\author{
CRISTEL ANTONIA RUSSELL \\ ANDREW T. NORMAN \\ SUSAN E. HECKLER*
}

\begin{abstract}
The consumption of television programming is of particular interest to consumer researchers because of the potential influence of television characters as referent others. Connectedness characterizes the intensity of the relationship(s) that viewers develop with television programs and their characters. We describe a threephased research program that develops and presents preliminary validation of a measure of connectedness. We differentiate connectedness from the related but distinct constructs of attitude and involvement. The potential of the connectedness scale to further our understanding of the consumption of television programming and its psychological and sociological effects on viewers are articulated and tested in a series of studies.
\end{abstract}

If you have 8 or more of these things, then you are obsessed!

You have a haircut just like one of the Friends.

You have/own/write for a Friends fan club.

You can tell people what the next episode is going to be about.

You tape every episode.

You can sing all of Phoebe's songs.

You have been to every site in Yahoo's list

of Friends Sites.

You have a chick, a duck, or a monkey.

You have a gold frame round the peep hole on the door.

You speak like Phoebe (i.e., "ooh," "yaha," "eeewwww").

You make loads of smart ass comments like Chandler.

You always talk about what happened on Friday morning.

You are constantly quoting Friends.

You spent afternoons sitting and watching old episodes of Friends.

When the new season came out on video, you went and bought it on the first day it was out.

You want to marry one of the cast of Friends. (Abridged version of a fan's list)

*Cristel Antonia Russell is assistant professor of marketing at San Diego State University, 5500 Campanile Drive, San Diego, CA 92182-8239; e-mail: crussell@mail.sdsu.edu. Andrew T. Norman is assistant professor of mar-
7 his obsession test, posted on the personal Web site of a fan of NBC's Friends, illustrates some of the more extreme manifestations of the consumption of regular television programming. Soap operas, situation comedies, dramas, and other television series that air regularly not only captivate the attention of many viewers but also provide a fertile environment where relationships between viewers and the program and its characters can develop. Despite their fictional nature, television characters may indeed appear as real people to viewers (Fiske 1992), or at least impart enough feelings of familiarity and intimacy that viewers may forge para-social relationships with them (Horton and Wohl 1956). The potential influence of TV characters as referent others (Newton and Buck 1985) makes it important for consumer researchers to capture the extent to which consumers develop relationships with the characters in TV programs and to study how those relationships affect consumers' experiences.

Our research seeks to investigate this phenomenon through the development of the construct of television con-

keting at Drake University, 2507 University Avenue, Des Moines, IA 503114505; e-mail: atnorman@iastate.edu. Susan E. Heckler is Distinguished Endowed Chair of Marketing at the University of St. Thomas, 100 LaSalle Avenue, Mail \#343TMH 331, Minneapolis, MN 55403; e-mail: seheckler @ stthomas.edu. The authors wish to thank Roy Kenneth Teas, Michael J. Barone, Chris Puto, Judy Zaichkowsky, Sidney Levy, Joe Belch, Bill Baker, Mickey Belch, and Heather Honea for their comments on early versions of this article. The authors also wish to thank the editor, the associate editor, and the reviewers for their helpful input. This research was supported by grants from the San Diego State University Foundation and the College of Business at San Diego State University. 
nectedness, characterized as the intensity of the relationships viewers develop with TV programs and the characters in those programs. Viewers indeed differ in the degree to which they develop relationships in a para-social television environment. At one end of the connectedness spectrum, a TV program may be viewed simply as a form of mindless entertainment. Viewers may feel positively toward the program and be attentive when watching it, but the extent of their connection stops there. At the other end of the spectrum, TV programs and their characters can become an obsession with which viewers constantly interact and around which they model their lives. Viewers may identify with the situations in the program, vicariously participate in the characters' experiences (Maccoby and Wilson 1957), or even develop para-social relationships with the television figures (Levy 1962). Like traditional consumer-brand relationships, consumer-program relationships evolve over time and may generate feelings of commitment, intimacy, and affective attachments with the program (Fournier 1998). However, program-triggered relationships bear an even greater resemblance to interpersonal relationships since viewers may also relate to the characters that evolve and interact in a parasocial television environment.

The nature of these relationships magnifies their significance to the study of television effects. The more deeply a viewer relates to a program and its characters, the greater the normative and informational influences he/she will receive and the stronger the resulting behavioral modeling effects (Nord and Peter 1980). Further, as the line that separates program from promotional content becomes increasingly blurry (Shrum 2003), it has become increasingly important to study not just how much television people watch or how much they like the programs but also how much they relate to the situations and characters in those programs and how such referential relationships affect their own consumption experiences.

In this article, we review the characteristics of the consumption of regular TV programming as a basis for defining connectedness. We then present a scale that measures the gradation in the intensity of these individual-program relationships. This scale can be used to depict the degree to which consumers develop relationships with TV programs and their characters and to explain how televised representations of consumption influence consumers. By providing a rich descriptor of how viewers relate to their TV programs and characters, our measure of television consumption extends beyond existing measures of the amount and type of television that people watch or general evaluations and emotional responses to those programs. In order to identify the possible dimensions of viewers' relationships with specific programs, we now turn to a review of the extant research on television programming and its effects on consumers.

\section{WHAT IS CONNECTEDNESS AND WHY DO WE NEED IT?}

Understanding television viewing and its consequences on the audience is of great importance to consumer re- searchers because of various effects that television programming has on consumers' lives. First, TV programs remain a major context for advertising messages and, as such, can generate certain emotional responses or feeling states (e.g., Pavelchak, Antil, and Munch 1988) or certain liking responses (Barwise and Ehrenberg 1987; Murry, Lastovicka, and Singh 1992) that affect the impact of the messages placed within it. In both of these cases, the focus is placed on the effect of program context on evaluations of commercials (Goldberg and Gorn 1987; Murry et al. 1992) or on recall for commercials (Pavelchak et al. 1988).

Second, TV programs themselves are influential because they depict and even model a myriad of consumption-relevant phenomena, such as the structure of family life, social roles, lifestyles and subcultures, or issues of gender, race, and class. Psychological effects of the programs themselves have only been studied in terms of the quantity of television viewing. Such studies show that the effects of heavy versus light viewing of a program on perceptions of real world phenomena (O'Guinn and Shrum 1997) can be explained by the frequency of exposure to television exemplars. More specifically, the more someone is exposed to television images, the more accessible that information is in memory and the more it becomes a heuristic when making social judgments (Shrum, Wyer, and O'Guinn 1998). In addition to establishing a connection between cumulative exposure and information accessibility, these studies suggest the possibility that the higher order effects of television viewing (i.e., its effect on attitudes and behaviors) are driven more by how veridical viewers perceive television information to be than simply by how much television they watch. This research further underscores the need to account for the relationships that viewers establish with those shows and characters, which likely boost such perceptions of realism.

Such relationships emerge because of the para-social interaction process that may develop between the viewers and the characters portrayed in their TV programs (Newton and Buck 1985). Because TV characters appear to live in similar time scales to their audience and exceed their textual existence (Fiske 1992), they may become referent others to the viewers. As referent others, characters provide strong models for viewers that become a reference point of identification (Maccoby and Wilson 1957), a source of social comparison (Richins 1991), and inspiration for goals that consumers choose to work toward (Hirschman and Thompson 1997). As a result, strong relationships may form between the viewers and the television characters that resemble interpersonal relationships (Levy 1962). These behavioral modeling effects (Nord and Peter 1980) are especially powerful because the dramatic nature of TV programming elicits expressions of feeling and verisimilitude rather than the counterargumentation usually associated with advertising (Deighton, Romer, and McQueen 1989).

Recognizing the limitations of current television audience measures, Russell and Puto (1999) introduced the construct of connectedness as a richer indicator of the nature and intensity of the relationship(s) between a viewer and a TV 
show. They proposed that connectedness extends beyond the mere viewing experience by capturing the extent to which a TV program contributes to a viewer's self and social identity. Although their qualitative investigation provides strong conceptual support for the introduction of connectedness and its contribution to the study of television consumption, there remains a need to develop an instrument to measure the construct and to inscribe it in a nomological network. Our literature review has reiterated the fact that a measure of TV program connectedness must extend beyond the emotional arousal and attentional intensity of the viewing experience and capture the para-social relationships viewers create with their TV programs and the characters in those programs.

Definition: We formally define connectedness as the level of intensity of the relationship(s) that a viewer develops with the characters and contextual settings of a program in the parasocial television environment.

With the conceptual underpinnings of connectedness now established, the remainder of this article describes our threephased research plan to develop and validate the instrument to measure it, in line with traditional scale development procedures (Churchill 1979; Gerbing and Anderson 1988). Phase 1 consisted of an item generation process and several exploratory factor analyses to establish the instrument. In phase 2, additional data were collected to validate the factor structure identified in phase 1 through confirmatory factor analysis. Phase 3 consisted of a series of studies to validate the predictive ability of connectedness on important psychological and social variables and assess the relationship between connectedness and several other indicators of television influence, namely, overall TV viewing, attitude toward the program, and involvement with the program.

\section{PHASE 1: SCALE DEVELOPMENT}

\section{Item Generation}

The exploratory stage of our research sought to generate a pool of items to characterize the relationships that individuals form with TV shows. This was accomplished both by collecting original focus group data and through a review of relevant literature.

Three 1-hr. focus groups were conducted at a southwestern university, each with groups of from five to nine undergraduate students (male and female) who participated on a voluntary basis. Questions asking respondents about their favorite shows, the characters on the shows, and the impact of such on their lives, served to probe the relationships of interest. Discussions were transcribed and analyzed in a systematic fashion. We complemented this analysis with a review of scales related to the consumption of TV programming. For instance, we adapted some of the uses and gratification themes from Rubin, Perse, and Powell's (1985) examination of viewers' relationships with newscasters. Some key descriptors of TV programs reported in previous research (e.g., escape) also echoed benefits mentioned in our focus groups (Lee and Lee 1995; Rubin and Perse 1987).

From this qualitative analysis, an initial battery of 85 statements was generated that reflected the totality of topics addressed in the focus groups plus important aspects of television consumption adapted from previous research. This set was reduced by eliminating redundant, ambiguous, and leading statements, as well as statements that overlapped the constructs of attitude (e.g., "I love all the episodes of __") or involvement (e.g., "I become emotionally involved when I watch _ "). The final set of 45 statements retained for further analysis was transformed into a questionnaire of fivepoint (strongly disagree to strongly agree) Likert scales.

\section{Exploratory Factor Analyses}

Data were collected from undergraduate students at a southwestern university who participated voluntarily $(n=$ 175). Respondents selected a TV program from a list of popular shows and completed the self-paced questionnaire based on that program. The final dataset consisted of observations based on 20 different shows, the most frequent being Seinfeld (31.4\%), Friends (16.6\%), Party of Five (13.1\%), ER (8.6\%), and X-Files $(6.3 \%)$.

Exploratory factor analysis was used to suggest dimensions and to construct a scale on the basis of the resulting factor loadings (Churchill 1979). An analysis of the screen plots suggested six underlying dimensions. We eliminated items that loaded on more than one factor as well as those with factor loadings below .60. This process reduced the scale to 16 items, with each of the six factors represented by two or three items, as depicted in table 1 . The coefficient alpha was .84.

\section{Scale Description}

The six factors represent the different manifestations of how viewers connect with their TV program and develop para-social relationships with the characters. Escape characterizes the cathartic element that connects a viewer to a TV program. As documented in previous studies (Lee and Lee 1995), people immerse themselves into a TV program because it helps them forget about their problems and provides an escape. The Modeling factor measures a social learning process by capturing the degree to which individuals relate their own life to the lives of the characters in the show. In focus groups, a common statement illustrating this phenomenon was that the viewers could relate to the characters and subsequently model their lives after them. Fashion measures how extensively a viewer is influenced by the characters' appearance. This notion was also described by Rubin and Perse (1987). The Imitation dimension measures the inclination for people to imitate the characters, likely due to the emotional stimulation of taking on another role (Lee and Lee 1995). This dimension came out strongly in the focus groups, as individuals were often imitating words, voices, and noises of characters in shows. Although related to the Modeling factor, Imitation represents a shallower ex- 
TABLE 1

FACTOR STRUCTURE MATRIX IN PHASE 1

\begin{tabular}{|c|c|c|c|c|c|c|}
\hline \multirow[b]{2}{*}{ Factor item } & \multicolumn{6}{|c|}{ Factor loading } \\
\hline & Escape & Fashion & Imitation & Modeling & Aspiration & $\begin{array}{l}\text { Parapher- } \\
\text { nalia }\end{array}$ \\
\hline \multicolumn{7}{|l|}{ Escape: } \\
\hline Watching __ is an escape for me. (ESCAPE) & .760 & .228 & .063 & .015 & -.074 & 177 \\
\hline helps $\overline{\mathrm{me}}$ forget about the day's problems. (FORGETPB) & .744 & .105 & .077 & .297 & .113 & .086 \\
\hline If I am in a bad mood, watching puts me in a better mood. (GOODMOOD) & .744 & .043 & .237 & .260 & .200 & .023 \\
\hline \multicolumn{7}{|l|}{ Fashion: } \\
\hline I like the clothes they wear on $\ldots$. (LKCLOTH) & .240 & .860 & -.121 & .128 & .030 & .010 \\
\hline I like the hairstyles on . (LIKEHAIR) & .167 & .860 & -.064 & .185 & .097 & .056 \\
\hline I often buy clothing styles that l've seen in __. (BUYCLOTH) & .027 & .772 & .031 & .215 & .032 & .198 \\
\hline \multicolumn{7}{|l|}{ (2) } \\
\hline $\begin{array}{l}\text { I imitate the gestures and facial expressions from the characters in } \\
\text { (IMITATE) }\end{array}$ & .112 & -.045 & .815 & .180 & .023 & .239 \\
\hline I find myself saying phrases from ___ when I interact with other people. & & & & & & \\
\hline (PHRASES) & .051 & .047 & .822 & .168 & .092 & .065 \\
\hline I try to speak like the characters in __. (SPEAKLK) & .068 & .053 & .768 & .202 & -.052 & .325 \\
\hline \multicolumn{7}{|l|}{ Modeling: } \\
\hline I learn how to handle real life situations by watching . (HNDLREAL) & .104 & .177 & .045 & .826 & .081 & .075 \\
\hline I get ideas from__ about how to interact in my own life. (IDEAINTR) & .090 & .173 & .306 & .789 & .107 & .025 \\
\hline I relate what happens in __ to my own life. (RELATLIF) & .229 & .264 & .143 & .662 & .078 & -.022 \\
\hline \multicolumn{7}{|l|}{ Aspiration: } \\
\hline I would love to be an actor in _.. (BEACTOR) & -.068 & .049 & .154 & .133 & .835 & .069 \\
\hline I would love to meet the characters of $\_$. (MEETCHAR) & .270 & .136 & .098 & .145 & .716 & .164 \\
\hline \multicolumn{7}{|l|}{ Paraphernalia: } \\
\hline I have objects that relate to __ (badge, book, picture, etc.). (OBJECTS) & -.016 & .085 & .111 & -.012 & .134 & .734 \\
\hline I read books if they are related to $\ldots$ (BOOKS) & .049 & .021 & .214 & .171 & .088 & .747 \\
\hline
\end{tabular}

NOTE.-Boldface depicts which factor (column heading) relates to which item (row heading). 
FIGURE 1

PATH MODEL WITH ONE HIGHER ORDER FACTOR (MODEL D)

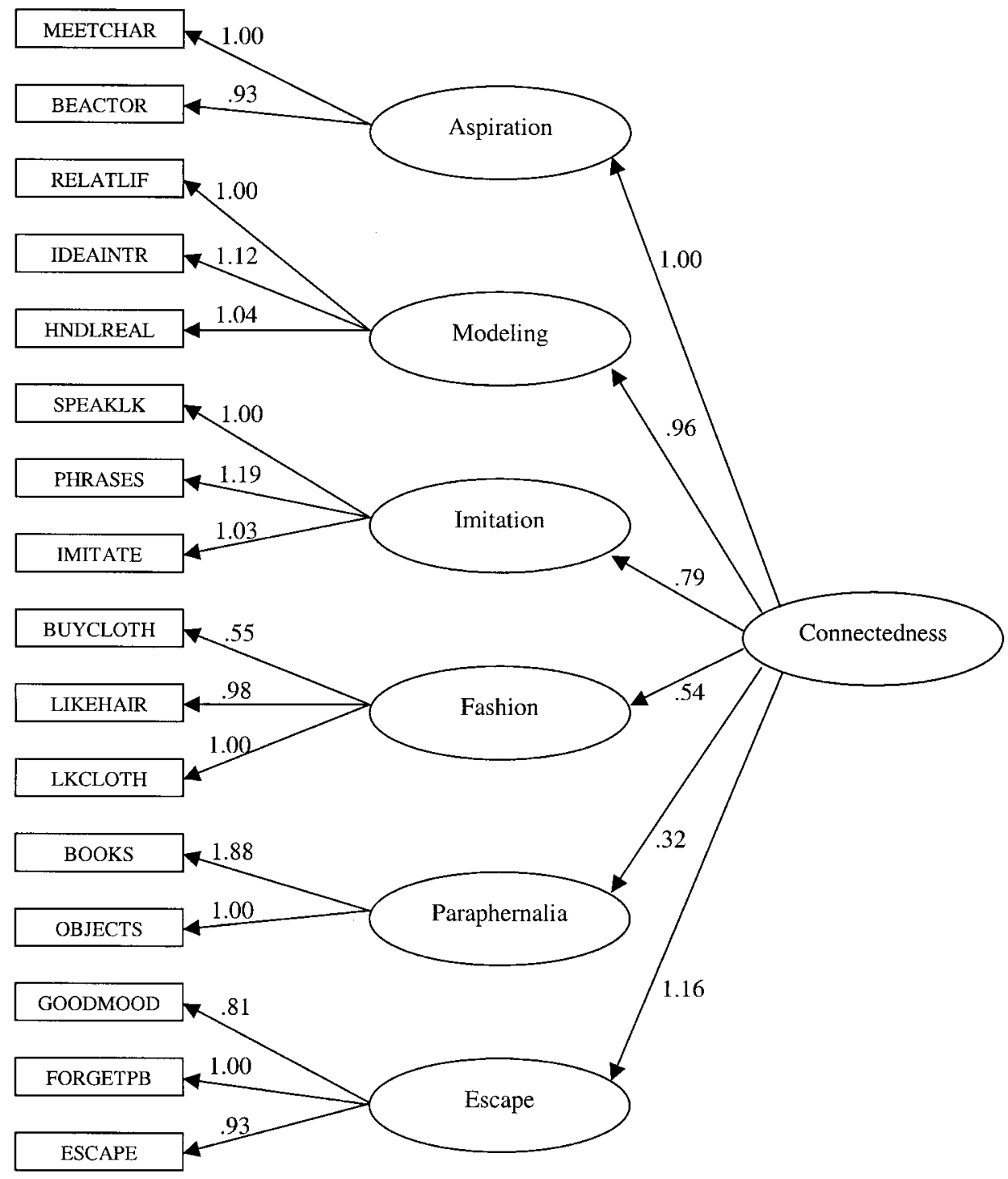

pression of identification with the characters, while Modeling is deeper and affects the more long-term aspects of a person's life. Aspiration identifies how people become so connected to a program that they actually aspire to be on the show or meet the characters. This element seems to be present only in those audience members who display the highest levels of connectedness. Finally, Paraphernalia measures the degree to which people collect items to bring the TV program and characters in their real world, such as books, magazines, or posters.

\section{PHASE 2: SCALE CONFIRMATION}

Having established the 16-item connectedness scale through factor analysis, we proceeded to phase 2 and col- lected subsequent data to confirm the factor structure and assess the scale's reliability. The multidimensional factor structure identified in phase 1 was subjected to a confirmatory factor analysis using data from the combined student samples $(n=613)$. The fit of the six-factor model emerging from the factor analysis was compared to three other confirmatory models to determine which provided the best fit (see fig. 1). The three models examined were a zero-factor or null model (model A), a single-factor model in which all 16 items comprised one factor (model B), and a six-factor oblique model in which correlations between factors were allowed (model $\mathrm{C}$ ). Model $\mathrm{C}$ fits significantly better than models $\mathrm{A}$ or $\mathrm{B}$, as indicated by the improvement in the chisquare measure of lack of fit between models (Jöreskog 
1993). In that model, the interfactor correlations ranged from .146 to .619. Because we view connectedness as a higher order construct explained by a number of related dimensions, we also tested a higher order model, model D, where a second-order factor represented the overall construct of connectedness. As can be seen in table 2, this model fits the data well and justifies the treatment of connectedness as a multifaceted but discrete construct.

\section{PHASE 3: SCALE APPLICATIONS AND INITIAL TESTS OF VALIDITY}

Phase 3 focused on external validation and nomological validity testing of our construct (Peter 1981). This section outlines a nomological network for connectedness and tests several theoretical propositions regarding the discriminant and predictive validity of the new construct through a series of studies. We position our construct in the stream of research on television influence and media effects by relating it to attitude toward the show, involvement, and overall TV viewing, and we introduce propositions related to the psychological and social consequences of connectedness.

\section{Discriminant Validity of Connectedness}

Attitude toward the Show. The attitude construct has been used extensively to reflect some degree of favor or disfavor toward an attitude object (Cacioppo, Gardner, and Berntson 1997). In a television context, measures of attitude toward the program, such as program evaluation (Barwise and Ehrenberg 1987) or program-elicited emotions (Murry et al. 1992), have been used to examine the program's effect on viewers' evaluations of advertising messages. We propose that connectedness goes beyond an overall evaluative response to the program and is thus distinct from attitude. Although a positive attitude toward a program may mediate the development of connectedness, it does not capture the fact that para-social relationships would emerge. A highly connected viewer has a deeper, more intimate relationship with the characters, which can take time to develop. Whereas a person could develop a positive attitude toward a program in a short period of time, or even a single viewing, the development of connectedness may require multiple viewings, to allow the relationship to progress from lower to higher levels of intimacy (Kelley et al. 1983). Although a positive attitude toward a program may mediate the devel- opment of connectedness, it does not capture the fact that such para-social relationships would emerge. Thus, we offer the following proposition.
P1: Connectedness and attitude toward the show are separate and distinct constructs.

Involvement. As suggested by research on program context effects (Park and McLung 1986), some of the core motivations for watching TV reflect the traditional construct of involvement. Although both involvement and connectedness stress the personal relevance of a TV program (Celsi and Olson 1988), they are different constructs. In a sense, the distinction between connectedness and involvement resembles the distinction between consumer-brand relationships and repeat purchase. Television programs may start by fostering enduring involvement with the program (Zaichkowsky 1985), over the course of repeat viewing, but end up absorbing their consumers in para-social relationships with the characters in the program (Fournier 1998), for instance, through connections and interactions with the fictitious characters in the show. Thus, we offer the following proposition.

\section{P2: Connectedness and involvement are separate and distinct constructs.}

Connectedness and Overall Television Viewing. The overall amount of TV viewing is commonly used as a measure of television influence. Although helpful in understanding viewers' construction of heuristics due to frequent exposure (Shrum et al. 1998), this measure does not characterize the relationships that consumers may selectively form with certain shows. In fact, conceptually, overall TV viewing and connectedness are potentially orthogonal constructs. For instance, a heavy TV viewer may be highly connected to various programs, or to some programs but not others, or even have no particular connection to any program. Similarly, light viewers may rarely watch TV but, when they do, they tune in to a specific program to which they are highly connected. Connectedness will allow for an examination of a variety of social and experiential aspects of this consumption experience, beyond examining the effects of mere repeated exposure to television images. Thus, we offer the following propostion.

TABLE 2

MODELS AND GOODNESS OF FIT INDICES FOR PHASE 2 CONFIRMATORY FACTOR ANALYSIS

\begin{tabular}{|c|c|c|c|c|c|c|c|c|}
\hline Model & Description & DF & $\chi^{2}$ & $\Delta \chi^{2}$ & $\mathrm{CFI}$ & NNFI & RMSEA & ECVI \\
\hline Model A & Null model & 136 & $21,880.66$ & & .000 & .000 & .511 & 35.805 \\
\hline Model B & One-factor model & 104 & $2,261.63$ & $19,619.03$ & .901 & .897 & .184 & 3.852 \\
\hline Model C & Six-factor model & 89 & 274.02 & $1,987.61$ & .991 & .987 & .058 & .654 \\
\hline \multirow[t]{2}{*}{ Model D } & Six-factor model with one & & & & & & & \\
\hline & higher order factor & 98 & 375.60 & 101.58 & .987 & .983 & .068 & .790 \\
\hline
\end{tabular}

NOTE. $-n=613$. 
P3: Connectedness and overall TV viewing are separate and distinct constructs.

\section{Consequences of Connectedness}

Psychological Consequences. Numerous studies have examined the cognitive processing of television images in general and the storage of program information in memory in particular (e.g., Shrum et al. 1998). Consumer researchers have also studied the effects of TV programming on memory for advertisements imbedded in the program (Gunter, Furnham, and Beeson 1997). The construct of connectedness suggests that the processing and storage of program-specific information will differ between individuals at high and low levels of the construct. Because of the strong relationships they enjoy with the program, highly connected viewers find the information in it more essential to their lives than less connected viewers. As a result, they process and encode program information in relation to their self (Russell and Puto 1999). This self-referential encoding involves both elaborative and organizational processes, which, in turn, lead to a memorial representation that incorporates both itemspecific and relational information (Meyers-Levy 1991), leading to improved memory and retention. This suggests several psychological consequences relevant to consumer researchers.

By definition, highly connected viewers are likely to consider the program content part of their world and to mold characteristics of their own life after the lives of the characters in the show. Because of the relationships they have with the characters, they are interested in the types of consumption displayed on the show, and, as a result, they pay more attention to these consumption portrayals and become more familiar with the premise and characters. These effects should be particularly notable in the realm of product placements, when real brands are placed in the program to enhance the characters' realism even further (Russell 2002). Thus, we offer the following proposition.

P4: As connectedness increases, memory for product placements improves, even when controlling for attitude toward the show, involvement, or overall TV viewing.

The increased processing of show- and character-related information also suggests that highly connected viewers would have a greater ability to imagine their favorite characters as real people, evolving on similar time scales, and using real brands. Such character-brand associations not only reflect the extent to which consumers elaborate on the program but also how easily they construct consumption schemas around the characters, which they can then use for selfexpression (Aaker 1999). The imagination literature defines imagination as "a cluster of images which have been brought together and produced in association with other mental processes such as past experiences, memories, thoughts, intentions, and various emotions" (Gordon 1985, p. 11). As connectedness develops, the resulting cognitive and emotional interaction between viewers and characters should increase the viewers' ability to employ imaginative resources toward the characters. Thus, we have the following proposition.

P5: As connectedness increases, the ability to imagine the characters as consumers of real products/brands also increases, even when controlling for attitude toward the show, involvement, or overall TV viewing.

Social Consequences. In addition to the influence that connectedness can have on an individual's own life, the socialization process around TV programs is also important. Qualitative investigations of television viewership through focus groups, internet fan forums, and in-depth interviews have revealed that TV programs can foster communities of consumption and contribute to viewers' social identity and social interactions (Kozinets 2001; Russell and Puto 1999). For instance, participants in focus groups conducted in phase 1 of this project frequently commented on their favorite programs with respect to their relationship with friends, family members, and acquaintances. The work on subcultures of consumption and brand communities clearly illustrates that a strong bond between a person and a TV program and its characters may serve as the basis for interpersonal interaction and social cohesion (Muniz and O'Guinn 2001). As an individual becomes more deeply bonded with a program, that individual will not only have a greater opportunity for social interaction but will also be more likely to seek out interactions with other viewers of the same program. The following proposition therefore is given.

P6: As connectedness increases, so will $(a)$ the frequency of show-related social interaction with others, $(b)$ the relationships within the community of co-viewers, and $(c)$ the size of the viewer's social network of co-consumers, even when controlling for attitude toward the show, involvement, or overall TV viewing.

\section{Methods}

Having established the theoretical rationale for our nomological network, we now describe the procedures for three studies conducted to test these relationships. The first study was conducted online and distributed via e-mail. Our goal was to cover a broad range of demographics, so as to paint a realistic and representative picture of the connectedness phenomenon and to maximize external validity. We used a professional online survey Web site to program the survey and collect the data. Invitations to complete the survey were sent out to 45,833 e-mail addresses purchased from a list service. We selected 111 e-mail lists on a broad variety of topics including, but not limited to, entertainment and/or television to provide as representative a cross section of television viewers as possible. A $\$ 500$ lottery was offered as incentive to encourage participation. Two additional studies were conducted with college students to further test the 
propositions that required tasks we deemed too demanding for a Web-based survey or experimental manipulations that were not practical online.

\section{Online Survey Instrument}

Upon entering the survey Web site, the respondents completed an initial set of questions on their general TV viewing habits. Overall TV viewing was measured using the number of hours per week respondents viewed particular program categories (O'Guinn and Shrum 1997). After being informed that the remainder of the survey would focus on a program of their choice, they were asked to type the name of a "specific TV series that airs regularly." As a means of assessing their history with this program, we asked them to indicate how long they had been watching the show and how many new and repeat episodes they watch each month.

Following these questions was a set of five-point Likert scales (strongly disagree/strongly agree) including the 16 connectedness items intermixed with a three-item brand community scale (McAlexander, Schouten, and Koenig 2002). This set was followed by the 10-item, seven-point personal involvement inventory (Zaichkowsky 1994), a three-item, seven-point attitude toward the show measure (I like it/I dislike it, good/bad, unpleasant/pleasant), and two five-point measures of the frequency of social interaction around the show ("how often do you talk about the show with others?" and "how often do you watch the show with others?"). To complement these social interaction measures, the respondents indicated "how many people (they) know personally who also watch this show?"

We assessed brand imagination by asking respondents to focus on one character in the show and "list a brand that (they) might imagine (their) favorite character using" and why. They were offered the opportunity to list and describe up to 10 brands. Following a brief definition of product placement, product placement recall was tested in a manner similar to the brand imagination test. Respondents were asked to type the brand or product name they remembered hearing or seeing during an episode of their show and to provide details about that occurrence. They could enter up to 10 different product placement occurrences. These answers were carefully scrutinized before computing the product placement recall scores so that only responses that included a brand or a product with detailed information about the placement occurrence were included in the analysis.

Finally demographic information was collected (gender, ethnicity, age, years of formal education, English as first language, country of residence, and ZIP code), as well as some control variables (how many people lived in their place of residence and household income).

Using data from this study and the follow-up college studies to be described later, we tested our propositions regarding the relationship of connectedness to attitude toward the show, involvement, and overall TV viewing, and the psychological and social consequences of connectedness. The next section describes the empirical findings from these tests.

\section{Descriptive Statistics and Distribution of Connectedness Scores for Web Sample}

A total of 12,263 individuals responded to our Web survey, providing a return rate of $26.8 \%$. Of those respondents, 10,181 were U.S. residents, with all but $2.8 \%$ speaking English as a first language. Significant variance resulted for gender (84.3\% females), ethnicity (86.4\% Caucasians, $5.6 \%$ African Americans, 2.6\% Hispanics, 2.0\% Asian Americans, and $1.1 \%$ Native Americans), age $(M=39.53, \mathrm{SD}=$ 12.11; ranging from 12 to 90 ), years of formal education $(M=13.92, \mathrm{SD}=2.32)$, and geographic distribution (all U.S. regions present based on ZIP codes; $6.8 \%$ lived outside the United States).

In terms of television viewing habits, the respondents watched an average of $32.66 \mathrm{hr}$. of television per week (slightly higher than the national average of 31.40 ; TVB Online 2002). The selected TV programs were categorized by genre, with the largest representations being dramas $(n=5,194)$, situation comedies $(n=2,780)$, soap operas $(n=911)$, action $(n=680)$, science fiction $(n=567)$, reality programs $(n=361)$, animated programs $(n=329)$, and dramedies $(n=178)$, an industry term referring to programs that bridge drama and situation comedy (e.g., Sex and the City). We focused our analyses on these eight genres and excluded those that did not fit our definition of regular TV program with recurring characters (e.g., sports or documentaries). Therefore, our final sample consisted of 11,000 complete responses. The most often selected shows mirrored the most popular shows of the time: Friends $(n=1,166)$, ER $(n=1,065)$, CSI $(n=661)$, and Law and Order $(n=621)$. The average length of time respondents had watched their show was 4.63 years $(\mathrm{SD}=5.53)$.

Connectedness scores covered the whole scale with a mean of 2.64 (SD = .68), ranging from 1 to $5(5=$ high $)$. Our instrument was thus able to capture the variance in intensity of the overall relationship(s) that viewers form with their shows thereby allowing us to test differences across connectedness levels. Unlike connectedness scores, which were normally distributed around the center point of the scale, attitude scores were skewed to the positive end of the scale. The extremely high mean attitude $(M=6.6 / 7.0$, $\mathrm{SD}=.66)$ reflects, per study instructions, the self-selection of shows that respondents watched. The involvement distribution was also skewed to the high end of the scale, with a mean of 5.7/7.0 $(\mathrm{SD}=.92)$. This reinforces the notion that it is possible to enjoy a show and be highly involved with it without necessarily being connected to it.

\section{Tests of Discriminant Validity}

To test our first set of propositions, we computed correlation coefficients and 95\% confidence intervals between connectedness and attitude toward the show, involvement, and overall TV viewing. Given our large sample size, all correlations were statistically significant at the .01 level and were examined for their practical significance. The correlation between attitude and connectedness was .257, with a 
confidence interval of .239-.276. This small correlation provides initial evidence of discriminant validity and support for proposition 1. There was a moderate positive correlation of .527 between involvement and connectedness, with a confidence interval of .511-.544. Although this test provides initial evidence for the distinction between connectedness and involvement, it is not conclusive and suggests the need for additional discriminant validity testing. Finally, the correlation between connectedness and overall TV viewing was .154 , with a confidence interval of .135-.173. This last correlational analysis provides evidence of discriminant validity between connectedness and overall TV viewing, in line with proposition 3. To further assess connectedness' superior predictive ability over these constructs, let us now turn our attention to its consequences.

\section{Tests of the Consequences of Connectedness}

The propositions regarding the psychological and sociological effects of connectedness were tested through a series of stepwise regression models. In each model, attitude toward the show, involvement, and overall TV viewing were first entered as independent variables and connectedness was added to the model in the second step. The predictive ability of connectedness on each dependent variable was tested by observing the improvement in model fit between step 1 and step 2 as well as the significance and size of the beta coefficient for connectedness. Further, the discriminant validity of connectedness was established by comparing the relative size of the beta coefficients. All independent variables were standardized so that these coefficients could readily be interpreted as indicators of their relative impact on each dependent variable (Neter et al. 1996).

Corresponding to propositions 4 and 5 , the psychological dependent variables were computed as the total number of product placements listed and the total number of brands imagined for the favorite character. Corresponding to proposition 6, the sociological dependent variables were the mean of the social interaction measures, the mean score on the three brand community items (McAlexander et al. 2002), and the size of the viewer's social network.

As can be seen in table 3 , connectedness was a significant and substantial predictor in all regression models (all $p$ 's $<.01)$, thereby providing support for its positive effect on product placement recall (proposition 4), brand imagination (proposition 5), and socialization (proposition 6). Furthermore, this effect occurred above and beyond that of the other variables, as indicated by the significant improvements in $R^{2}$ between step 1 and step 2 (all $p$ 's $<.01$ ). In all but one model, the magnitude of the standardized coefficient of connectedness was greater than that of any of the other independent variables, thereby validating its unique and superior effect on each dependent variable. We note that connectedness and involvement had equivalent effects on the amount of social interaction around the program.

To further illustrate the effects of connectedness, we divided respondents into low and high levels of connectedness and compared the means of each dependent variable. In support of proposition 4, the highly connected individuals recalled significantly more product placements from the show than did the low-connected individuals $(M=.31$ vs. $M=$ $.18, t(10,697)=11.65, p<.01)$. In line with proposition 5 , highly connected individuals were able to imagine significantly more brands for their favorite character than low-connected individuals $(M=1.17$ vs. $M=.91, t(10,697)=$ $13.82, p<.01)$.

Proposition 6 was also supported, as highly connected viewers interacted significantly more around the show than low-connected individuals $(M=3.78$ vs. $M=3.17$, $t(10,564)=32.85, p<.01)$. A similar pattern of results emerged with the brand community measure: highly connected viewers had a stronger sense of community around the show than low-connected viewers $(M=2.44$ vs. $M=1.31, t(10,697)=69.51, p<.01)$. Finally, highly connected viewers reported significantly larger social networks than low-connected viewers $(M=9.87$ vs. $M=6.27$; $t(10,332)=6.96, p<.01)$. The data thus support proposition 6: connectedness is significantly related to socialization around the program.

\section{Additional Studies}

Because the format of the online survey did not allow respondents to elaborate on their answers, we complemented

TABLE 3

REGRESSION RESULTS FOR ONLINE STUDY

\begin{tabular}{|c|c|c|c|c|c|c|}
\hline Dependent variable & Constant & $\begin{array}{c}\beta \\
\text { connectedness }\end{array}$ & $\begin{array}{c}\beta \\
\text { attitude }\end{array}$ & $\begin{array}{c}\beta \\
\text { involvement }\end{array}$ & $\begin{array}{c}\beta \\
\text { overall } \\
\text { TV viewing }\end{array}$ & $\begin{array}{c}\Delta R^{2} \\
\text { (step } 1-\text { step 2) }\end{array}$ \\
\hline \multicolumn{7}{|l|}{ Long-term recall of } \\
\hline Imagined brands & $1.051^{\star \star}$ & $.147^{\star *}$ & $.040^{* *}$ & .018 & .048 & $.015^{\star \star}$ \\
\hline Brand community & $1.938^{\star *}$ & $.656^{* *}$ & $-.119^{* *}$ & $.136^{\star *}$ & $.033^{\star \star}$ & $.306^{\star *}$ \\
\hline Social interaction & $3.470^{* *}$ & $.240^{\star \star}$ & $.036^{\star \star}$ & $.260^{\star \star}$ & $.031^{\star *}$ & $.041^{\star \star}$ \\
\hline Size of social network & $8.064^{* *}$ & $.089^{* *}$ & -.013 & .015 & $.045^{\star \star}$ & $.006^{\star *}$ \\
\hline
\end{tabular}

NOTE.-All independent variables are standardized. Step 1: regression without connectedness independent variable.

${ }^{\star *} p<.01$. 
it with two studies. Study 1 was a controlled experiment designed to measure short-term memory following exposure to a brief segment of Seinfeld. After viewing the program, subjects ( $n=104)$ completed a series of open-ended questions designed to test unaided recall for specific visual and auditory elements in the episode, followed by a corresponding recognition test, and a series of scales, among them connectedness and involvement. Memory scores were computed based on the percentages of correct responses for each of the audio and visual and free and aided recall. A multivariate repeated measures analysis was conducted on the four memory scores, using connectedness levels (high vs. low, median split), involvement levels (high vs. low, median split), and previous exposure (seen vs. not seen) as betweensubject factors. The analysis revealed a marginally significant main effect for connectedness $(F(4,92)=2.101$, $p=.087)$ and previous exposure $(F(4,92)=3.517, p=$ $.05)$, but the effect for involvement was not significant $(F(4,92)=.498, p>.10)$. As predicted, highly connected viewers recalled significantly more audio and visual elements than low-connected viewers. These differences were significant across tests, as indicated by an analysis of marginal means: $37.58 \%$ versus $49.36 \%$ on the free recall audio test $(p<.05), 51.54 \%$ versus $62.36 \%$ on the free recall visual test ( $p=.079), 60.13 \%$ versus $69.23 \%$ on the aided recall audio test $(p<.05)$, and $58.26 \%$ versus $66.48 \%$ on the aided recall visual test ( $p=.058$ ). These results demonstrate that connectedness is related to short-term memory for components of the program.

Study 2 provided another opportunity to test the relationship between connectedness and long term memory through the recall of product placements. We asked respondents $(n=99)$ to list brands or products that they remembered seeing or hearing at one time in Friends and to describe that instance. We compared the number of placements retrieved from memory across high and low connectedness levels (median split). Highly connected viewers recalled significantly more brands than low-connected viewers $(M=$ 2.16 vs. $M=.39, t(97)=4.25, p<.01)$. Thus, as anticipated, highly connected individuals have a greater propensity to retrieve information about the show and the consumption environment, both from short-term and long-term memory.

Data from study 2 also corroborate the relationship between connectedness and brand imagination. As in the online study, respondents were asked to list the brands that they imagined their favorite character might use in real life and to provide a rationale for each. Again, highly connected viewers listed significantly more brands than low-connected individuals $(M=3.22$ vs. $M=1.31, t(97)=4.49, p<$ $.01)$. The qualitative responses with the rationale for each of the brands listed provide interesting complementary insights to the elaborative process. For instance, one respondent who listed a total of nine brands for Joey, explained that his favorite character would use Scope Mouth Wash because he "needs good breath for the ladies," buy Trojan condoms because he "sleeps with a bunch of women," and eat Lay's potato chips because "he eats a lot of junk food watching TV." Many respondents imagined Rachel as a person who would read Cosmo and In Style, so as to "know the latest trends," and buy brands such as Armani, Charles David, or Tiffany, because "she is always stylish and dressed to impress." She would also use Tigi hair products, because "her hair is symbolic of our generation and everyone sees it and tries to emulate the style," or drink Diet Coke, because "she is concerned about her weight but likes to have fun." Alternatively, Monica is viewed as using such brands as Lysol, because "she is picky about cleaning," and T-Fal, because "she is a chef and needs good pots and pans." These data clearly reflect the fact that highly connected individuals not only easily imagine their favorite characters in real life but also can retrieve detailed character information from memory and this phenomenon is not simply due to greater involvement.

\section{Summary of Findings}

This program of research showed that the connectedness construct and its measurement instrument can significantly further our understanding of the consumption of TV programming and its effects on viewers. As a means of establishing the construct's discriminant validity, we demonstrated that connectedness is conceptually and empirically different from attitude toward the program, involvement, and overall $\mathrm{TV}$ viewing. In order to begin establishing its predictive validity, we showed that it is a significant predictor of both short- and long-term memory for program information and of of brand imagination and that it is significantly related to the size and amount of interactions within the viewer's social network of co-consumers. Further, our research efforts have included a broad cross section of TV viewers, and we have shown that the construct is relevant and applicable to different demographic groups.

\section{IMPLICATIONS AND FUTURE RESEARCH}

The objective of this research was to develop a better understanding of the consumption of regular television programming through a study of the relationships that viewers develop with TV programs and their characters. Our intent was to establish a measure that would advance the study of television consumption in all fields by complementing the standard quantitative measures of audience size and amount of viewing time with a richer, more descriptive instrument. We have proposed connectedness as a multidimensional construct to capture the intensity of the relationship(s) that viewers develop around TV programs. Through a three-phase and broadly based research program, we have introduced and tested a reliable instrument to measure this construct. In addition, a series of studies has shown the relationship of connectedness to other measures, as early steps in the validation process.

We recognize that validity testing of a newly established construct is an ongoing effort. This research provided evidence that the connectedness construct is unique from other 
constructs. However, we acknowledge the need for further discriminant and nomological validity testing, in particular to fully differentiate connectedness from involvement and attitude. More rigorous statistical testing of our validity propositions requires a wider range of attitude and involvement levels to avoid issues related to our positively skewed distributions. Thus, efforts to more fully validate the connectedness construct should include a broader array of consumers, programs, and genres. Such research would also allow for the investigation of whether certain programs or genres are particularly prone to trigger higher levels of connectedness.

In addition to this issue, additional validation efforts are needed to further test the multifaceted structure of connectedness. We have demonstrated that connectedness can be treated as a unique higher order construct. However, its first-order multidimensionality must be further tested across a variety of genres and situations.

The evidence supporting the relationships between viewers and programs calls for future research in the area of program context effects and advertising effectiveness. Existing research on the effects of TV program content has mainly focused on how program content affects mood, which, in turn, affects ad processing on the evaluation and processing of advertisements placed within the program (Goldberg and Gorn 1987; Pavelchak et al. 1988). The construct of connectedness provides a new means for studying the effects of programming on advertising. As an alternative to traditional mood manipulations, connectedness should have direct effects on how advertising is evaluated. However, in contrast to the blanket attitude toward the show-attitude toward the ad relationship (Murry et al. 1992), connectedness is likely to affect ad processing as a function of the type of products advertised and their fit with the program's content and characters.

More readily, the connectedness construct is valuable to assess the effectiveness of product placements. Although the practice of product placement is an increasingly popular promotional strategy, and one that has significantly contributed to the blurring of the lines between entertainment and promotional content (Shrum 2003), academic investigation of how such placements affect consumers is still in its infancy. We have presented evidence of the effect of connectedness on memory for brands and products placed in the program, but additional research is needed to study these effects at the attitudinal and behavioral level. Since connectedness characterizes the degree to which TV characters appear as referent others, it should follow that more highly connected viewers not only pay more attention to those product placements but also develop positive attitudes toward brands associated with the characters they connect to and have a stronger desire to emulate the consumption schemas depicted in the program in a self-expression process (Aaker 1999).

This article has highlighted the fact that one of the main contributions of the connectedness scale is overcoming the limited nature of previous audience measures based on au- dience size or volume of viewing, attitude toward the program, and even involvement. As a more descriptive and qualitatively rich measure of audiences, connectedness provides new directions for this area of research. This is particularly relevant given recent changes in technology and the rapid fragmentation of TV audiences. As media options increase and audience sizes decrease, the old models of watching television are in serious need of revision. Identifying audiences by connectedness level instead of audience size or viewing frequency has scholarly implications for studying television consumption as well as practical implications for evaluating the value of advertising space and time. We thus anticipate that the connectedness scale will have a significant impact on many streams of research, including advertising and product placement effects and audience measurement.

Finally, this research suggests implications for broader social science studies of the development and maintenance of relationships in general. In an increasingly mediated world, research on how connectedness relationships evolve over the course of a person's life (Levy 1962) would uncover the mechanisms by which consumers form and sustain such relationships (Fournier 1998). We may find that certain individuals are more prone to develop private but intense relationships with mediated or even virtual characters or that others develop para-social relationships with such characters as a substitute for real relationships. As we unearth the processes through which consumers "connect" with fictitious characters in popular culture vehicles, we may also be able to better understand how individuals in today's environment use such relationships to manage stress, where such relationships can be valuable versus detrimental to people's life experiences, or how commonalities of connectedness between people contribute to more positive, long-lasting relationships. Many other such extensions are left to be uncovered and explored as continuing research utilizes the connectedness scale, continues to build support for its validity, and begins to examine some of the questions raised throughout this discussion.

\section{[Dawn Iacobucci served as editor and Eric J. Arnould served as associate editor for this article.]}

\section{REFERENCES}

Aaker, Jennifer L. (1999), "The Malleable Self: The Role of SelfExpression in Persuasion," Journal of Marketing Research, 36 (February), 45-57.

Barwise, T. Patrick and Andrew S. C. Ehrenberg (1987), "The Liking and Viewing of Regular TV Series," Journal of Consumer Research, 14 (June), 63-70.

Cacioppo, John T., Wendi L. Gardner, and Gary G. Berntson (1997), "Beyond Bipolar Conceptualizations and Measures: The Case of Attitudes and Evaluative Space," Personality and Social Psychology Review, 1 (1), 3-25.

Celsi, Richard L. and Jerry C. Olson (1988), "The Role of Involvement in Attention and Comprehension Processes," Journal of Consumer Research, 15 (September), 210-24.

Churchill, Gilbert A., Jr. (1979), “A Paradigm for Developing Bet- 
ter Measures of Marketing Constructs," Journal of Marketing Research, 16 (February), 64-73.

Deighton, John, Daniel Romer, and Josh McQueen (1989), "Using Drama to Persuade," Journal of Consumer Research, 16 (December), 335-43.

Fiske, John (1992), Television Culture, London: Methuen.

Fournier, Susan (1998), "Consumers and Their Brands: Developing Relationship Theory in Consumer Research," Journal of Consumer Research, 24 (March), 343-73.

Gerbing, David W. and James C. Anderson (1988), "An Updated Paradigm for Scale Development Incorporating Unidimensionality and Its Assessment," Journal of Marketing Research, 25 (May), 186-92.

Goldberg, Marvin E. and Gerald J. Gorn (1987), "Happy and Sad TV Programs: How They Affect Reactions to Commercials," Journal of Consumer Research, 14 (December), 387-403.

Gordon, Rosemary (1985), "Imagination as Mediator between Inner and Outer Reality," Arts in Psychotherapy, 12 (1), 11-15.

Gunter, Barrie, Adrian Furnham, and Christopher Beeson (1997), "Recall of Television Advertisements as a Function of Program Evaluation," Journal of Psychology, 131 (5), 541-53.

Hirschman, Elizabeth C. and Craig J. Thompson (1997), "Why Media Matter: Toward a Richer Understanding of Consumers' Relationship with Advertising and Mass Media," Journal of Advertising, 26 (Spring), 43-60.

Horton, Donald and R. Richard Wohl (1956), "Mass Communication and Para-social Interaction," Psychiatry, 19 (August), 215-29.

Jöreskog, Karl G. (1993), "Testing Structural Equation Models," in Testing Structural Equations Models, ed. Kenneth A. Bollen and J. Scott Long, Newbury Park, CA: Sage, 294-316.

Kelley, Harold H., Ellen Berscheid, Andrew Christensen, John H. Harvey, Ted L. Huston, George Levinger, Evie McClintock, Letitia Anne Peplau, and Donald R. Peterson (1983), "Analyzing Close Relationships," in Close Relationships, ed. Harold H. Kelley, New York: W. H. Freeman, 20-67.

Kozinets, Robert V. (2001), "Utopian Enterprise: Articulating the Meanings of Star Trek's Culture of Consumption," Journal of Consumer Research, 28 (June), 67-88.

Lee, Barbara and Robert S. Lee (1995), "How and Why People Watch TV: Implications for the Future of Interactive Television," Journal of Advertising Research, 35 (6), 9-18.

Levy, Sidney (1962), "Phases in Changing Interpersonal Relations," Merrill-Palmer Quarterly of Behavior and Development, 8 (2), 121-28.

Maccoby, Eleanor E. and William Cody Wilson (1957), "Identification and Observational Learning from Films," Journal of Abnormal and Social Psychology, 55 (1), 76-87.

McAlexander, James H., John W. Schouten, and Harold Koenig (2002), "Building Brand Community," Journal of Marketing, 66 (January), 38-54.

Meyers-Levy, Joan (1991), "Elaborating on Elaboration: The Distinction between Relational and Item-Specific Elaboration," Journal of Consumer Research, 18 (December), 358-67.

Muniz, Albert M., Jr., and Thomas C. O’Guinn (2001), "Brand Community," Journal of Consumer Research, 27 (March), 412-32.

Murry, John P., Jr., John L. Lastovicka, and Surendra N. Singh (1992), "Feeling and Liking Responses to Television Programs: An Examination of Two Explanations for Media-Con- text Effects," Journal of Consumer Research, 18 (March), $441-51$.

Neter, John, Michael H. Kutner, Christopher J. Nachtsheim, and William Wasserman (1996), Applied Linear Statistical Models, Chicago: Irwin.

Newton, Barbara J. and Elizabeth B. Buck (1985), "Television as a Significant Other," Journal of Cross-Cultural Psychology, 16 (3), 289-311.

Nord, Walter R. and Paul Peter (1980), "A Behavior Modification Perspective on Marketing," Journal of Marketing, 44 (January), 36-47.

O’Guinn, Thomas C. and L. J. Shrum (1997), "The Role of Television in the Construction of Consumer Reality," Journal of Consumer Research, 23 (March), 278-94.

Park, C. Whan and Gordon W. McLung (1986), "The Effect of TV Program Involvement on Involvement with Commercials," in Advances in Consumer Research, Vol. 13, ed. Richard Lutz, Provo, UT: Association for Consumer Research, 544-48.

Pavelchak, Mark A., John H. Antil, and James M. Munch (1988), "The Super Bowl: An Investigation into the Relationship among Program Context, Emotional Experience, and Ad Recall," Journal of Consumer Research, 15 (December), 360-67.

Peter, J. Paul (1981), "Construct Validity: A Review of Basic Issues and Marketing Practices," Journal of Marketing Research, 18 (May), 133-45.

Richins, Marcia L. (1991), "Social Comparison and the Idealized Images of Advertising," Journal of Consumer Research, 18 (June), 71-83.

Rubin, Alan M. and Elizabeth M. Perse (1987), "Audience Activity and Soap Opera Involvement," Human Communication Research, 14 (2), 246-68.

Rubin, Alan M., Elizabeth M. Perse, and R. Powell (1985), "Loneliness, Parasocial Interaction, and Local Television News Viewing," Human Communication Research, 12 (2), 155-80.

Russell, Cristel A. (2002), "Investigating the Effectiveness of Product Placements in Television Shows: The Role of Modality and Plot Connection Congruence on Brand Memory and Attitude," Journal of Consumer Research, 29 (December), 306-18.

Russell, Cristel A. and Christopher P. Puto (1999), "Rethinking Television Audience Measures: An Exploration into the Construct of Audience Connectedness," Marketing Letters, 10 (4), 393-407.

Shrum, L. J. (2003), The Psychology of Entertainment Media: Blurring the Lines between Entertainment and Persuasion, New York: Erlbaum.

Shrum, L. J., Robert S. Wyer, and Thomas C. O'Guinn (1998), "The Effects of Television Consumption on Social Perceptions: The Use of Priming Procedures to Investigate Psychological Processes," Journal of Consumer Research, 24 (March), 447-58.

TVB Online (2002), “Consumer Media Usage,” http://www.tvb .org/tvfacts/index.html.

Zaichkowsky, Judith Lynne (1985), "Measuring the Involvement Construct," Journal of Consumer Research, 12 (December), 341-52.

(1994), "The Personal Involvement Inventory: Reduction, Revision, and Application to Advertising," Journal of Advertising, 23 (December), 59-70. 
Copyright of Journal of Consumer Research is the property of Journal of Consumer Research, Inc. and its content may not be copied or emailed to multiple sites or posted to a listserv without the copyright holder's express written permission. However, users may print, download, or email articles for individual use. 